\title{
Actual Issues of Risk Management in the Market of Digital Financial Assets
}

\author{
J.I. Shatohina ${ }^{1, *}$ A.V. Kochetkov ${ }^{2}$ \\ ${ }^{1}$ Don State Technical University, Rostov-on-Don, Russia \\ ${ }^{2}$ Rostov State University of Economics, Rostov-on-Don, Russia \\ *Corresponding author. E-mail: salute@shatohina.ru
}

\begin{abstract}
Digital financial assets hide many of the risk management problems that emerged with the birth of the first digital currency, Bitcoin. The article discusses specific risks in the market of digital financial assets and elements of a system for managing such risks. The analysis of the survey data of professional market participants was carried out and the main risk groups in the digital financial assets market were identified, while for the purposes of comparison, the classic market of financial assets was considered. The system of digital financial assets market management system proposed at the legislative level will allow broadcasting and effective implementation of market regulation measures proposed by the state and the Central Bank. At the same time, a system of commercial and nonprofit organizations that will carry out their activities or will be involved as suppliers (performers, contractors) for implementing state programs providing the conditions for the development of the digital financial assets market can become a market development infrastructure.
\end{abstract}

Keywords: blockchain technology, bitcoin, cryptocurrency, digital platform, digital financial asset, digital economy, token, investments, national currency, management, mining, pricing mechanism, risks, regulation

\section{INTRODUCTION}

The market for digital financial assets has been showing strong growth since the first half of 2019. According to Coinmarketcap.com, since the beginning of this year, the total capitalization of the world market has grown more than 15 times - from $\$ 17.7$ billion to $\$ 310$ billion. The cost of bitcoin increased during the year from the level of 3844 US dollars to the level of 12859 US dollars (more than 3.3 times). Trading volume with bitcoin is now several billion dollars a day, while a year earlier the daily turnover was tens of millions of dollars.

The rapid growth of the uncontrolled market causes concern among central banks in several countries, including the Russian Central Bank. The Bank of Russia believes that the rapid growth of digital financial assets carries risks for the national and global economy. The formation of a "bubble" in the market of digital financial assets can lead to significant consumer losses. There are also risks of their use for money laundering and terrorist financing.

At the same time, considering a new economic phenomenon, it is necessary to understand that the risks are associated not only with market speculation and criminal use. Many projects related to digital financial assets and ICOs are based on technologies: distributed data storage, pplications for trading, payment instruments. It is not possible to ignore the fact that new technological trends have arisen in the world that can change the foundations of the financial system.

Risks are an integral part of any economic system and business. Risks in the market of digital financial assets arose simultaneously with the advent of the turnover of such assets, as well as the economic relations associated with it. An objective analysis of the sphere of digital financial assets and the risks contained therein is hindered by the lack of information about the market for such assets in Russia and similar assets in foreign markets. In addition to the limited amount of information, the complexity of the analysis is related to the problems of creating the technology itself, on which the functioning of digital financial assets is based, and a high level of uncertainty.

The risk, as you know, is a complex and multifaceted phenomenon, having many mismatching bases. This leads to the emergence of a number of definitions of the concept of "risk" from various points of view. At the same time, today there is no unambiguous definition of the concept of risk, which is explained by the lack of fixing and regulation of the term in Russian legislation, in real economic practice and management activities, however, a study of existing interpretations of the essence of risk allows us to divide them into two main areas.

\section{KEY COMPONENTS OF RISK MANAGEMENT IN THE DIGITAL FINANCIAL ASSETS MARKET}

\subsection{Classification of specific risks in the market of digital financial assets}

The first group of opinions is based primarily on the disclosure of the relationship of risk with the concepts of 
uncertainty, random events, frequency and probability, and risk is considered as the probability of a loss of values, including financial, as a result of activities if the external environment and internal factors change in direction other than that provided by plans and calculations. The understanding of risk as uncertainty is based on such largescale concepts as the probability theory of B. Pascal and P. Fermat, statistical procedures and methods proposed by J. Bernoulli, A. Muavr, F. Galton, scientific works in the field of investment portfolio management G. Markowitz, G. Modigliani, the work of N. Blake and M. Schols, as well as many other researchers and practical developers.

The idea of risk as a quantitative measure of uncertainty was first expressed by F. Knight. F. Knight defined risk as "measurable uncertainty", "probabilistic (stochastic) certainty" [1]. O. Morgenstern and J. Neumann established the relationship of the concepts of "uncertainty" and "risk" and gave a probabilistic-mathematical interpretation of risk [6]. The theory of entrepreneurial risk by A. Marshall and A. Pigou argues that in a market economy an enterprise operates in conditions of uncertainty, in connection with which profit is random and the entrepreneur is interested not only in the amount of profit, but also in the range of its possible fluctuations [2]. Understanding the risk of an economic entity as the likelihood of adverse effects is given by I.A. Blanc [4], B. Milner, and F. Liis. "Risk exists wherever there is uncertainty about the future," Y.D. Vishnyakov and N.N. Radaev.

On the other hand, a number of researchers consider risk as a potential, numerically measurable possibility of losses, this approach is called economic [8]. So, L.N. Tepman notes that risk is the possibility of adverse situations during the implementation of plans and budget execution of the enterprise [5]. D.S. Goncharov expresses the opinion that profit is always associated with a certain level of risk, and profit is a risk premium, i.e. the higher the risk, the higher the expected profit. I.T. Balabanov gives the definition of risk as the "possible danger of loss" arising from the specifics of various natural phenomena and human activities [10]. O.A. Grunin and S.O. Grunin is understood as a "risk factor in business", a reason, a driving force that can "create danger or lead to damage, loss" [9].

Economic interpretations of risk reveal the content of this category through its essential functions, "probabilistic", "statistical" focus on the possibility of identification. Thus, both approaches to understanding the essence of risk occupy a certain place in the process of analysis and management of this economic category [3].

There are also two main approaches to identifying the principles and signs of risk classification:

- building a general or substantive classification for the specific content of each type and type of risk;

- specific classifications.

The criteria for the subject classification are the most general characteristics inherent in all types of risk characteristics, including risks in the market of digital financial assets:

- sources, factors or causes of damage;

- objects of vulnerability to danger;
- the magnitude of the consequences;

- dependence on the time factor;

- typicality and regularity of occurrence;

- impact assessment criteria;

- parameters of the magnitude or size of the risk;

- degree of measurability and predictability.

On the general subject classification, specific risk classifications are usually built that are used to manage risks in certain areas of economic activity: insurance, foreign exchange markets, the banking sector, construction, trade, stock markets, etc. This principle can be traced in the works of I.T. Balabanova, E.S. Stoyanova, A.S. Shapkin [7]. The specific classification in each case will reflect the characteristics of the industry, market, business itself, as well as the uniqueness of the current economic situation and the specifics of the manifestation of risks.

So, when classifying specific risks in the securities market, the following groups are taken into account:

- market risks;

- regulatory risks;

- informational risks;

- technological risks;

- risks associated with the specifics of the turnover of financial assets.

The given classification groups do not cover all the criteria and classification possibilities of the market in question, however, for the purposes of the study, such aggregation is considered appropriate. In our opinion, the closest market for identifying and classifying the risks of digital financial assets is the classic market for financial assets. The basis for such a comparison can serve as its key features:

- financial assets express investor capital in various types of financial instruments (mainly in securities) in order to obtain acceptable income;

- financial assets are formed in the financial market as a result of the exchange between its entities that are short of cash (issuers, borrowers) and those who have a surplus of funds (investors, creditors);

- financial assets can be unique (for example, a loan agreement) or have a standard form and circulate in the stock market (securities);

- part of financial assets characterizes only financial obligations (loans and borrowings), and part determines ownership (shares).

To identify and classify specific risks in the market of digital financial assets, it is important to identify groups of homogeneous risks, which will provide a number of important advantages. Given the existing approaches to the classification of risks in classical financial markets, as well as the features of the digital financial assets market, the author proposed the following specific classification taking into account a number of criteria (Figure 1):

- market conditions;

- organizational and legal characteristics and the information field of the market of digital financial assets;

- features of the technology on which the functioning of the digital financial assets market is based;

- extraordinary characteristics. 

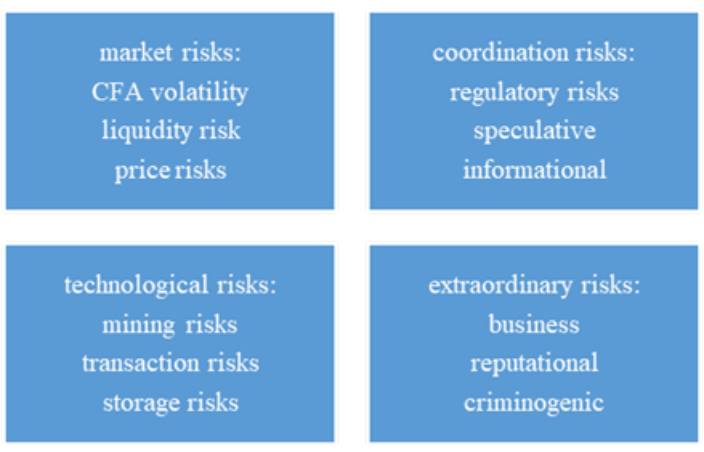

Figure 1 Risks in the Digital Financial Assets Market

Market risks in the market of digital financial assets are risks that are directly related to digital financial assets and have a macroeconomic nature, that is, the sources of market risks are the dynamics of macroeconomic indicators of the financial system - market indices, interest rate curves, etc. Three key An element of the market risk of digital financial assets: the volatility risk of digital financial assets, liquidity risk and price risk.

Coordination risks can significantly affect the market of digital financial assets and have a global character: regulatory risks; speculative; and informational. Coordination risks can be associated with any aspect of the digital financial assets market: information, news, prohibitions at the level of domestic legislation, international regulation.

Among other types of risks, technological risks should be taken into account: mining risks, transaction risks, storage risks.

Also, in our opinion, organizations working with digital financial assets carry additional extraordinary risks: business, reputational and criminogenic.

To assess the degree of risk, we conducted a survey of participants in the market of digital financial assets, as a result of which we determined the level of risks, the indicator of congruence of the degree of influence and the level of individual risks in the market of digital financial assets. Conclusions are based on the understanding of empiricism, which is best formed by researchers in professional and applied fields.

The survey was proposed by 623 Russian experts and market participants in digital financial assets:

- developers of the technology on which the digital financial assets market operates;

- issuers ("miners");

- investors, including private ones;

- representatives of the banking sector;

- representatives of commercial organizations using digital financial assets.

For a survey of experts and market participants, 4 groups of questions were proposed for each type of risk:

- how do you assess the degree of influence of risk on the market of digital financial assets;

- how do you assess the degree of influence of risk on the classic financial market;
- evaluate the level of risk in the market of digital financial assets on a scale of 1 to 10 ;

- rate the level of risk in the classic financial market on a scale of 1 to 10 ;

The respondents had the opportunity to answer only the first two groups of questions (if the assessment of the level of risk was difficult) or all the questions on the questionnaire. A fully completed questionnaire was received from 95 respondents, which is $15.25 \%$. The remaining 528 survey participants answered the first two groups of questions. Moreover, the data can be considered sufficiently reliable for the total population of 7,230 people. (number of respondents). The estimated level of confidence in the statistical result was $95 \%$ with an error of $10 \%$, which corresponds to the recommended value. Interactive survey was conducted on the platform www.survio.com.

The category "high risks" includes answers with 5 or more points; "Medium risks" - from 1 to 5 points (corresponds to the interval from $10 \%$ to $50 \%$; "relatively low" - to 1 point (corresponds to the interval from 0 to $10 \%$ ), (see table 1). The table shows the percentage of answers respondents corresponding to each risk level interval.

More than $50 \%$ of respondents rated most of the risks in the digital financial assets market as "high". More than $70 \%$ of the survey participants noted currency, price and speculative risks as high. Regulatory risk with an assessment of more than 5 points allocated $69.7 \%$. Risks with an average level, according to survey participants: transactional (69.1\%), business $(54.1 \%)$ and reputational $(67.2 \%)$. None of the risks in the digital financial assets market fell into the "relatively low" category.

Risks in the classical financial market, in most cases, respondents classified as "medium". The respondents considered high the liquidity risk (68.9\%) and the speculative risk (72.1\%). Relatively low respondents considered the risk of emissions (51.8\%), storage (50.4\%), business risk (74.1\%) and reputation (76.4\%).

\subsection{Digital Risk Market Risk Management System}

The rapid growth of the uncontrolled market causes concern among central banks in several countries, including the Russian Central Bank. The Bank of Russia believes that the rapid growth of digital financial assets carries risks for the national and global economy. The formation of a "bubble" in the market of digital financial assets can lead to significant consumer losses. There are also risks of their use for money laundering and terrorist financing.

At the same time, considering a new economic phenomenon, it is necessary to understand that the risks are associated not only with market speculation and criminal use. Many projects related to digital financial assets and ICOs are based on technologies: distributed data storage, trading applications, payment instruments. It is not possible to ignore the fact that new technological trends have arisen in the world that can change the foundations of the financial system. 
Table 1 Comparative risk analysis in the market of digital financial assets and in the classical financial market *

\begin{tabular}{|c|c|c|c|c|c|c|}
\hline \multirow[b]{2}{*}{ Types of risks } & \multicolumn{3}{|c|}{ Digital Financial Assets Market } & \multicolumn{3}{|c|}{ Classic financial market } \\
\hline & $\begin{array}{c}\text { High } \\
>50 \%(5 \\
\text { points) }\end{array}$ & $\begin{array}{c}\text { Middle } \\
10-50 \% \text { (from } 1 \text { to } \\
5 \text { points) }\end{array}$ & $\begin{array}{c}\text { Low } \\
<10 \% \text { (less than } \\
1 \text { point) }\end{array}$ & $\begin{array}{c}\text { High } \\
>50 \%(5 \\
\text { points) }\end{array}$ & $\begin{array}{c}\text { Middle } \\
10-50 \% \text { (from } 1 \text { to } \\
5 \text { points) }\end{array}$ & $\begin{array}{c}\text { Low } \\
<10 \% \text { (less than } \\
1 \text { point) }\end{array}$ \\
\hline $\begin{array}{l}\text { CFA / currency volatility, } \\
\text { Central Bank }\end{array}$ & 72,8 & 27,1 & 0,1 & 32,8 & 64 & 3,2 \\
\hline liquidity risk & 64,1 & 35,9 & 0 & 68,9 & 30,8 & 0,3 \\
\hline price risks & 82,6 & 14,8 & 2,6 & 41,6 & 56,8 & 1,6 \\
\hline regulatory risks & 69,6 & 29,2 & 1,2 & 29,1 & 68,1 & 2,8 \\
\hline speculative & 73,4 & 25,4 & 1,2 & 72,1 & 26,6 & 1,3 \\
\hline informational & 54,2 & 43,1 & 2,7 & 27,5 & 68,9 & 3,6 \\
\hline mining risks (emissions) & 57,3 & 42,4 & 0,3 & 13,9 & 34,3 & 51,8 \\
\hline transaction risks & 28,1 & 69,1 & 2,8 & 25,8 & 73,9 & 0,3 \\
\hline storage risks & 67,4 & 28,3 & 4,3 & 19,4 & 30,2 & 50,4 \\
\hline business & 39,4 & 54,1 & 6,5 & 16,2 & 9,7 & 74,1 \\
\hline reputational & 29,1 & 67,2 & 3,7 & 21,6 & 2 & 76,4 \\
\hline criminogenic & 64,9 & 33,9 & 1,2 & 24,5 & 71,6 & 3,9 \\
\hline
\end{tabular}

* response rate (\%) based on the processing of 95 questionnaire survey participants

Many tools can be used both for the good and the detriment. This also applies to the dangers of using digital financial assets in money laundering and terrorist financing. This also applies to Internet technology, where using cryptocurrencies you can order murders and finance terrorism. Market regulation and the creation of mechanisms to protect the market for digital financial assets should help solve this problem. The creation of such mechanisms is based on the creation of a risk management infrastructure in the market in question (see Figure 2).

\begin{tabular}{ll}
\hline & government regulation \\
\cline { 3 - 3 } & market participants \\
& regulatory framework \\
aggregates of yif financial assets \\
regulatory organizations, Educational \\
centers
\end{tabular}

Figure 2 Risk management system components in the digital financial asset market

\section{CONCLUSION}

In additin to developing the regulatory framework for state regulation, the author believes that it is necessary to finalize the main directions of the development strategy for financial technologies in the financial market of the Bank of Russia, affecting certain aspects of the development of the digital financial assets market. When developing certain provisions of a document or a system of documents, priority objectives for the development of the market for digital financial assets should be identified, such as:

- promoting economic growth by providing competitive

- access to turnover in the market of digital financial assets, risk insurance instruments;

- improving the level and quality of life of citizens of the Russian Federation through the use of instruments of the market in question;

- creating conditions for the growth of technologies and the market for digital financial assets (for example, the creation of specialized technology parks as institutes of infrastructure supporting the development of the digital financial assets market).

The designated goals can be achieved by:

- formation of a trusting environment;

- development of competition in the financial market;

- maintaining financial stability;

- ensuring the availability of digital financial assets.

The regulation of digital financial assets in individual countries must be approached with caution. Countries that will include the digital economy in their legal field as much as possible will receive some global advantages of an early start in attracting investors and taxpayers. 
cryptoasset regulatory landscape study. Cambridge: Cambridge Centre for Alternative Finance.

[4] I.A.Blank Financial management, Kiev: Omega, 2017,765 p.

[5] L.N. Tepman, V.A. Napërov, Innovative Economics: Textbook. manual for university students studying in the fields of economics and management, M.: UNITY-DANA, 2017, 275 p.

[6] Robert J. Leonard From Parlor Games to Social Science: Von Neumann, Morgenstern, and the Creation of Game Theory 1928-1944, Source: Journal of Economic Literature, 1995, Vol. 33, No. 2, 730-761.

[7] A.S. Shapkin, A.S. Shapkin, Economic and financial risks. Valuation, management, investment portfolio Shapkin, Spb.: Dashkov\&K, 2017, 328 p.

[8] Hileman, G., \& Rauchs, M. (2017). Global cryptocurrency benchmarking study. Cambridge Centre for Alternative Finance.

https://cdn.crowdfundinsider.com/wpcontent/uploads/2017/04/Global-CryptocurrencyBenchmarking-Study.pdf. Accessed 14 Sept 2019.

[9] O. A. Grunin, S. O. Grunin Economic security of the organization, Spb.: Publishing House PETER, 2015, $456 \mathrm{p}$.

[10] Balabanov I.T. Fundamentals of financial management: textbook. allowance for secondary special institutions, 3rd ed., Ext. and reslave. - M.: Finance and Statistics, 2016, 528 p.

[3] Blandin, A., Cloots, A. S., Hussain, H., Rauchs, M., Saleuddin, R., Allen, J. G., et al. (2019). Global 